\title{
A Criança e o Ambiente Social: Aspectos Intervenientes no Processo de Desenvolvimento na Primeira Infância
}

\author{
Alcylanna Nunes Teixeira ${ }^{1}$; Karla Rossana Gomes Lôbo ${ }^{2}$; Ana Teresa Camilo Duarte ${ }^{3}$
}

\begin{abstract}
Resumo: O presente estudo abordou questões sobre o ambiente social da criança na Primeira Infância e respectivas influências para o desenvolvimento. Quando em contato com o ambiente social a criança vivencia experiências únicas e desafiadoras, que exigem resposta de interação e ajustamento ao meio, geralmente manifestada por comportamentos motivados diante de estímulos sensorialmente captados e interpretados na relação da criança no seu ambiente social. $\mathrm{O}$ objetivo foi explorar os aspectos sociais as quais a criança é exposta na Primeira Infância. Para tanto, importante se fez estudar as vivências, implicações, intervenientes e respectiva interação com o ambiente social no processo de desenvolvimento da criança. Para o método se utilizou a leitura seletiva e reflexiva durante todo o estudo, este do tipo exploratório, com caráter qualitativo, através de revisão de literatura, a partir do referencial de pesquisas atualizadas e desenvolvidas ao longo dos estudos sobre desenvolvimento humano infantil. As bases de dados foram advindas predominantemente de livros, revistas e periódicos, especialmente do banco de dados da Biblioteca Virtual em Saúde - Psicologia - BVSPSI, delimitando predominantemente SciELO no período circunscrito nos últimos 5 anos para artigos e dissertações, que se fazem relevantes para com a temática estudada, considerando os descritores: Desenvolvimento, Primeira Infância, ambiente social, modelo bioecológico; estes subsidiaram a compreensão sobre as características peculiares na Primeira Infância compreendida de 0 a 3 anos. Através desse estudo foi possível compreender a Primeira Infância como um período fundamental para o desenvolvimento da criança, uma vez que, essa é exposta as exigências do meio desde a relação primeira com a mãe, se estendendo para o núcleo familiar e demais parentes e amigos próximos, que podem promover ou limitar o desenvolvimento saudável da criança. Conclui-se que o ambiente social da criança a desafia, principalmente frente às relações estabelecidas e os estímulos aos quais ela é submetida na Primeira Infância, implicando na capacidade adaptativa e no desenvolvimento de habilidades necessárias para fases subsequentes do seu Ciclo vital.
\end{abstract}

Palavras chaves: Ambiente Social. Desenvolvimento. Contexto. Primeira Infância.

\section{The Child and the Social Environment: Intervening aspects in Development Process in Early Childhood}

\begin{abstract}
The present study addressed questions about the social environment of the child in early childhood and their influences on development. When in contact with the social environment the child lives unique experiences and challenging, requiring interaction response and adjustment in half, usually manifested by motivated behaviors before sensorially stimuli picked up and interpreted in respect of the child in its social environment. The objective was to explore the social aspects which the child is exposed in early childhood. To this end, important if you did study the experiences, implications, actors and their interaction with the social environment in the process of child development. For the method used selective reading and reflective throughout the study, This exploratory type, with qualitative character, through review of the literature, from the updated research and referential developed over the studies on child human development. The databases were coming predominantly from books, magazines and periodicals, especially the database of Virtual Health Library
\end{abstract}

\footnotetext{
${ }^{1}$ Graduação em Psicologia pela Faculdade Leão Sampaio (FALS); Especialista em Saúde Mental (FALS); Pós Graduando em Ciências da Educação e Docência do Ensino Superior pela Faculdade Vale do Salgado (FVS); Formação em Psicologia do Esporte e do Exercício Físico pela CEPPE e ASPPE (em andamento). Psicóloga com atuação em Saúde Mental; Docente (FVS); Preceptora e Supervisora de Estágio Básico Supervisionado em Psicologia nas áreas social, educacional e da saúde pela FVS;

${ }^{2}$ Graduação em Licenciatura Plena e em Psicologia Clínica, com formação ludoterápica pela Universidade Estadual da Paraíba - UEPB. Mestre em Desenvolvimento Regional Sustentável pela UFCA-CE (2014); Especialista em Psicologia da Criança e do Adolescente FACISA-CG; Violência Doméstica - USP-SP; e, Docência do Ensino Superior - FALS-JN (2009). Formação em Brinquedista - Associação Brasileira de Brinquedotecas ABBrinไUSP-SP.

${ }^{3}$ Bacharel e Graduado em Serviço Social pela a FALS - Faculdade Leão Sampaio, tendo como carreira acadêmica um período de 8 Semestres e especialista em Serviço Social e Humanização pela FJN - Faculdade de Juazeiro do Norte. Professora especialista da Faculdade Vale do Salgado.

Autor correspondente: E-mail: profkarlinhalobo@hotmail.com
} 
Id on Line Revista Multidisciplinar e de Psicoloqia

Id on Line Multidisciplinary Journal and Psycology

- Psychology - BVSPSI, bordering predominantly the period limited in recent SciELO 5 years for articles and dissertations, which are relevant to the topic studied, whereas the descriptors: early childhood development, social environment, model bioecológico; These subsidized the understanding about the peculiar characteristics in early childhood comprised of the 3 year 0 . Through this study was possible to understand the early childhood as a period critical to the child's development, once, that's exposed Middle requirements since the first relationship with the mother, extending to the core family and other relatives and close friends, that can promote or limit the healthy development of the child. It is concluded that the child's social environment the challenges, especially in the face of the relationships established and the stimuli to which it is subjected in early childhood, resulting in adaptive capacity and the development of skills necessary for subsequent phases of their life cycle.

Keywords: Social Environment. Development. Context. Early Childhood.

\section{Introdução}

O presente estudo aborda questões ligadas ao contexto em que a criança vivencia suas primeiras experiências de vida no mundo, a partir do nascimento à aproximadamente três anos, período dito Primeira Infância. Esta é estudada atualmente nas mais diversas áreas do conhecimento humano, não por ser considerada uma incógnita, mas por indicar os primórdios da construção de repertórios cognitivos, psicológicos e, especialmente, os de ordem social no campo do desenvolvimento humano.

A criança foi expressamente negligenciada até meados do século XVII, pois era subestimada em suas necessidades peculiares, considerada um adulto em miniatura, que não desempenhava papel social produtivo, e assim, não era reconhecida como sujeito em seu meio, nem mesmo a infância enquanto fase integrada ao ciclo vital humano (MÜLLER; NUNES, 2014).

Segundo Àries (1981) a necessidade de cuidados com a criança se dava mais comumente em famílias abastardas economicamente, onde o interesse era de preservação do sobrenome para a manutenção dos bens materiais a serem passados de geração à geração na mesma família. Importante então era manter a criança viva até que pudesse contribuir produtivamente para com a permanência desta tradição, ignorando potencialidades da criança na Primeira infância.

A Psicologia do Desenvolvimento coadunando com demais saberes das ciências humanas e da saúde, reconhece os primeiros anos de vida como basilar, sendo as primeiras experiências da criança registradas e aprendidas na captação e aquisição de mecanismos 
constantemente adaptativos ao seu ambiente. Na Primeira Infância, que está compreendida de 0 à aproximadamente 3 anos segundo Feldman e Papalia (2013, p.127), a criança é intensamente desafiada em um processo ininterrupto de interpretação dos estímulos biopsicosociais, que sinalizam as implicações no desenvolvimento.

A problemática aqui apresentada circunscreve o período supracitado, que indica a Primeira Infância como cenário que exploração e cuidados para com primeiras experiências da criança, colocando a criança na condição de ser humano em desenvolvimento, uma vez que a infância tem sido alvo de violações, descasos e negligências, apontando implicações para com o processo de desenvolvimento.

As características e necessidades infantis segundo Shaffer e Kipp (2012) remetem a um período multidimensional, ao qual a criança vivencia os principais conteúdos que irão compor um repertório contínuo para sua relação com o meio. Assim, importante se fez estudar características peculiares da Primeira Infância e as influências do ambiente para a criança em desenvolvimento, tornando o interesse pessoal para com o estudo, relevante ao âmbito social diante do zelo para com a infância, a família aos seus cuidados primeiros e primordiais, e ainda, contribuições científicas para com comunidades acadêmicas.

Assim, o objetivo deste artigo é compreender o ambiente em que a criança é exposta na Primeira Infância e as implicações para com o processo de desenvolvimento. Para tanto, importante se fez estudar as vivências, implicações, intervenientes e respectiva interação com o ambiente social no processo de desenvolvimento da criança.

A hipótese que instiga o percurso deste aponta para a falta de atenção e de cuidados com a estimulação no ambiente, que pode comprometer a construção de um alicerce para a criança em desenvolvimento, predizendo riscos para fases subsequentes desse mesmo processo. Neste sentido, o presente estudo, dar-se-á em torno das condições de desenvolvimento oferecidas a criança na Primeira Infância, como os estímulos aos quais ela é submetida promovendo possibilidades de incitá-la ou inibi-la em seu processo de desenvolvimento e transformações contínuas diante dos desafios enfrentados desde seus primeiros contatos com o mundo (CUNHA; BENEVIDES, 2012).

No que diz respeito ao método, foi desenvolvido estudo do tipo exploratório, com caráter qualitativo, por meio de revisão de literatura, considerando o levantamento feito através de banco de dados de livros, periódicos e pesquisas com referências afins ao 
Id on Line Revista Multidisciplinar e de Psicologia

Id on Line Multidisciplinary Journal and Psycology

desenvolvimento infantil. Como critério de inclusão, os estudos sobre psicologia do desenvolvimento humano; desenvolvimento infantil; primeira infância; ambiente e contextos da criança; importância da infância para o desenvolvimento; modelo bioecológico de desenvolvimento humano; no tocante aos critérios de exclusão, estudos que se detém ao desenvolvimento da adultez, envelhecimento e finitude; Contextos Meso, Macro e de Exossistemas na abordagem Bioecológica; Processos de adoecimentos ligados ao desenvolvimento (LIMA; MIOTO, 1994).

Os dados foram coletados através da BVS-PSI (Biblioteca Virtual em Saúde Psicologia) delimitando predominante SciELO, considerando publicações dos últimos 5 anos para artigos e dissertações, e aqueles que extrapolam o período, foram inclusos por critério de relevância teórica. O levantamento feito em 16 livros impressos, desses, 9 foram utilizados, dentre eles, Àries (1981), Winnicott (1982), Biaggio (1988), conferindo destaque a Feldman e Papalia (2013), Shaffer e Kipp (2012) por situarem as contribuições teóricas como as de Jean Piaget no período de 1952 - 1970 e Erick Erickson 1950-1982, dentre outras. Em caráter virtual, o acervo de é 596 publicações descritas por infância, 197 contemplam os critérios de inclusão e exclusão; 98 descritos sobre desenvolvimento infantil onde 28 oferecem aportes considerando os descritores: Desenvolvimento, Primeira Infância, ambiente social, Modelo Bioecológico.

A leitura seletiva e reflexiva acompanhou todo o estudo, e fez-se necessário ampliar as inferências acerca do Desenvolvimento Infantil, dada a importância das primeiras experiências e representações da mesma nem seu contexto, dialogando com as contribuições do viés Bioecológico Bronfrenbrenneano no período de 1979 - 1999 com saberes respectivos e aportes significativos à compreensão dos desafios enfrentados pela criança em seu ambiente.

Estudos e pesquisas afins possibilitaram a apreensão sobre as peculiaridades da Primeira Infância, as dimensões da criança em desenvolvimento, de modo especial de 0 à 3 anos, as primeiras experiências, o contexto das relações e os intervenientes no processo de desenvolvimento. Desse modo, as contribuições teóricas subsidiaram a produção do trabalho no transcorrer do curso, onde o interesse pela temática instigou a exploração de temáticas relacionadas ao desenvolvimento na Primeira Infância, durante o período compreendido entre março de 2014 e abril de 2015. 
Id on Line Revista Multidisciplinar e de Psicologia

Id on Line Multidisciplinary Journal and Psycology

\section{Criança em Desenvolvimento: Características e Peculiaridades}

A compreensão biológica sobre o início da vida e respectiva importância da infância, compõe-se da fecundação, seguida pelo ciclo embrionário - quando na tuba uterina se dá o processo da formação do zigoto pela penetração do espermatozóide no óvulo e desenvolvimento do feto - seguido da gestação ao parto, assim como todos os anos que acompanham a infância. Porém, a dimensão biofisiológica não basta para (re) montarmos a base do Desenvolvimento Humano considerando o mosaico subjetivo destes primeiros anos de existência para cada ser humano (SHAFFER; KIPP, 2012).

Após os 266 dias, em média, em que cada criança expecta para nascer juridicamente ${ }^{1}$, já recebe diversos estímulos através do corpo materno, com a possibilidade do mundo externo, que aos poucos vai se tornando mais próximo de ser vivenciado como tal. Segundo Biaggio (1988), a experiência do parto é o primeiro, e porque não dizermos um dos maiores desafios enfrentados pela criança, uma experiência que influenciará condições futuras para o desenvolvimento, pois se trata de um fenômeno intenso, vivenciado e percebido concretamente, e em proporção semelhante, representado subjetivamente em diversas configurações, pelos pais, filhos e profissionais da saúde que acompanham este momento.

Segundo Shaffer e Kipp (2012) o parto - que remete a transição do ambiente interno para externo - não por acaso, representa-se estressante para o bebê, não apenas pela necessidade do equilíbrio dos batimentos cardíacos e fluxo cerebral, mas também, para alertar funcionalmente e dar ciência ao recém nascido da ocorrência especial desta experiência. $\mathrm{O}$ mesmo deve agora adaptar-se ao meio ambiente complexo e diferente do que conhecera no ventre materno e ao nascer já reage interagindo, comunicando-se e efetuando primeiras aprendizagens pelo momento experiencial que se deu a partir do nascimento, "o choro inicial é indicação de quando os pulmões se encheram e começaram a funcionar, é o sinal mais evidente da vitalidade do recém nascido" (BIAGGIO, 1988, p.83) e, é essa vitalidade que desafia e o convoca ao novo mundo, que exige excessivamente das condições biológicas primárias do bebê e seu potencial ligado aos órgãos dos sentidos.

${ }^{1}$ A criança é reconhecida legalmente a partir do Registro de Nascimento, dispondo responsabilidades a sociedade em geral, a família e ao estado. (ÀRIES,1981). 
As sensações vivenciadas pelos bebês são os estímulos primeiros para as respostas ao meio. Dentre outros estudiosos, Erickson em meados de 1952 apontava para a importância das primeiras experiências vividas pela criança como elemento indispensável para o desenvolvimento de condições favoráveis ao processo na Primeira Infância, onde as habilidades, conquistas e virtudes adquiridas nesse primeiro momento implicariam na qualidade do desenvolvimento da criança para com fases subsequentes. Jean Piaget por volta de 1945 ja revelava subsídios sensórios - motores e suas contribuições basilares para o desenvolvimento da criança, o que compôs seu marco desenvolvimental de 0-2 anos de idade. (SHAFFER; KIPP, 2012).

Nos estudos sobre o desenvolvimento, comumente presumi-se a hereditariedade e a genética como elementos fundantes, mas não somente se apresentam como peças determinantes dessa análise. Não existe gravidez, nem mães, nem bebês iguais e segundo Biaggio (1988), não existem repetições nem mesmo contextos idênticos de parto, para sozinhos darem respostas comportamentais das pessoas no decorrer de suas vidas. O ambiente social ao qual a criança é exposta se torna um agente fundamentalmente co-responsável pelos estímulos e seus potencializadores, seja proporcionando um ambiente desafiador e favorável ao desenvolvimento saudável, ou limitador de experiências indispensáveis ao processo, retardando-o diante das possíveis apreensões.

Há influência do ambiente social desde o momento do parto segundo Shaffer e Kipp (2012), e o fato já impulsionou diversas pesquisas em torno desse fenômeno, a exemplo, exploraram a variável da presença do pai ou a permanência da criança na enfermaria com a mãe e não no berçário hospitalar. O importante faz-se acrescentar que, mesmo reconhecendo o vínculo biológico consanguíneo, há o diferencial que é o desenvolvimento do vínculo afetivo pelas influências do meio ambiente.

O recém nascido então, é compreendido em sua complexidade, no espaço clínico e familiar já assume o status de ser vivente e incorporado ao ambiente sociocultural, considerando também que "bebês nascem com a capacidade de aprender com aquilo que vêem, ouvem, cheiram, degustam e tocam, além de terem certa capacidade de lembrar o que aprenderam" (FELDMAN e PAPALIA, 2013 p.17), na medida em que interage como o mundo, o bebê gradativamente desenvolve habilidades para com o seu ambiente, as respostas 
são dadas na medida em que o vínculo materno e familiar estimula e permite que ocorra envolvimento e desenvolvimento.

\begin{abstract}
Após 1 ano, as mães que tiveram "contato estendido" ainda estavam mais envolvidas com os seus filhos, e estes sobressaíram em testes de desenvolvimento físico e intelectual comparados aos do grupo de horário estabelecido. Aparentemente, quanto maior o contato entre mães e filhos após o parto, maior a feição das mães por eles, o que, por seu turno, pode tê-las motivado a interagirem de maneira mais estimulante com seus bebês (SHAFFER e KIPP, 2012, p.149, grifo do autor).
\end{abstract}

Esta mãe implicará em condições básicas de estímulos aos quais dispõem e expõe a criança, favorecendo ao desenvolvimento satisfatório de habilidades para lidar com as exigências intrínsecas e extrínsecas, a mãe se faz importante para a criança durante todo o processo e pela função que desempenha, proporcionando vínculo afetivo suficientemente adequado, não necessariamente por ser mulher ou mãe biológica. Segundo Biaggio (1988, p.122) no tocante ao estabelecimento de vínculo afetivo, esta mãe "homem ou mulher, genitor ou não" assume papéis diante das necessidades, mediando e responsabilizando-se pelo desenvolvimento da criança diante das condições oferecidas no contexto.

É possível compreender a importância daquele que exerce função materna, que possa mediar e proporcionar ambiente favorável para que a criança se desenvolva. Há estudos no tocante às crianças adotivas, que ressaltam indicativos importantes quando essas são acolhidas em lares adotivos e se desenvolverem de forma satisfatória, a partir do momento que lhes são oferecidas ambientes com condições estimulantes e que favorecem a qualidade afetiva do papel materno no relacionamento circunscrito ambiente - criança - cuidador, pois são os estímulos posteriores ao nascimento que irão apontar as expressões e relações afetivas porvindouros (FELDMAN; PAPALIA, 2013).

Para Winnicott (1982) os pais, especialmente a mãe, auxiliam determinantemente na transição e relação da criança do seu mundo interno ao externo, mediando experiências, apresentando o mundo, primeiros objetos ou símbolos funcionais do ambiente familiar, do novo mundo, do contexto social no qual esta inserida. Para o autor, quanto melhor e suficiente desempenhar sua função de apresentar o mundo e cuidar, a mãe sustenta e maneja relações positivas com a criança, proporcionando melhores possibilidades de promover um desenvolvimento suficientemente saudável para as demais fases do processo. 
Nesse cenário, Biaggio (1988) acrescenta contribuições ao compreender que a mãe influencia no processo de socialização e a criança por sua vez, numa condição de dependência "continua a mediar sua relação com o mundo e dela depende em grande parte que ele possa achá-lo confiável, ordenado e bom ou caótico, confuso e perigoso" (BIAGGIO, 1988, p. 87). Ao andar, por exemplo, a criança testa aprendizagens motoras e estratégias cognitivas, mas somente se lança a experiência pela contínua estimulação à autonomia a partir da confiança adquirida.

\begin{abstract}
Ao caminhar, a criança exerce uma grande atividade motora e de exploração do mundo material; por isso é absorvido por cada novidade que descobre. Desse modo, estabelece relações mais estreitas com os objetos, desfruta da sua pequena autonomia e do distanciamento, de certa indiferença em relação a sua mãe (BIAGGIO, 1988, p. 181).
\end{abstract}

Experiências como a de andar, já caracterizam relações mais elaboradas de confiança e autonomia, que certamente foi estimulada e desenvolvida de modo favorável nos primeiros meses de vida da criança, permitindo essa des-envolver, no sentido de sair do envolvimento com a mãe. Desenvolver difere do caráter que concebe crescimento, o ultimo aponta o evoluir cronologicamente e dentro de padrões que caracterizam fases esperadas de desenvolvimento, já este, diz respeito a um processo que envolve questões biopsicossocioespiritual, expondo o desenvolvimento em um processo amplo e complexo frete ao crescimento. (ROMANI; LIRA, 2014).

O Crescimento aqui vem apontando para resultado e, desesenvolvimento para processo, construção. Desse modo, Erickson, (1952 apud SHAFFER; KIPP, 2012) ressalta a importância das primeiras experiências na Primeira Infância, é nesta que o bebê inseguro, indefeso, limitado emocionalmente e com necessidades básicas urgentes, desenvolve repertório de comunicação com o mundo, coadunando com a idéia proposta por Gauy e Costa Junior em expor que:

\footnotetext{
o ambiente e o organismo, em contínua interação, estabelecem mudanças progressivas de contexto e de comportamento, que podem ser analisadas funcionalmente ao longo do desenvolvimento ou por determinados episódios comportamentais em um dado momento (GAUY e COSTA JUNIOR apud DESSEN e COSTA JUNIOR, 2005, p56).
}

A relação da criança com o mundo é constantemente desafiadora, mas é nesse contexto que lhe proporciona tronar-se uma criança de sentimentos complexos, e ainda com capacidade de compreendê-los e controlar diante das circunstâncias às quais é exposta, são 
Id on Line Revista Multidisciplinar e de Psicoloqia

Id on Line Multidisciplinary Journal and Psycology

essas condições quem dizem da consequente forma de interação que a criança aos poucos estabelece com o seu meio. o ambiente influencia o desenvolvimento ao proporcionar estímulos que mantêm alguns comportamentos e extinguem outros, apontando o contexto de interação da criança, assim como subscrito:

[...] com o desenvolvimento, as interações da criança com o ambiente tornam-se mais complexas e amplas, podendo mostrar momentos diferenciados, conhecidos como estágios, descritos por suas propriedades causais e/ou funcionais e manifestações fisiológicas, comportamentais e sociais (GAUY e COSTA JUNIOR apud DESSEN e COSTA JUNIOR, 2005, p56).

Neste sentido, a exposição gradativa aos estímulos externos auxilia na composição do parecer infantil diante dos acontecimentos do mundo, das pessoas e respectivas emoções e comportamentos gerados, possibilitando a inserção ativa da criança no contexto biopsicossocial, onde a mesma está intrincada num processo de personalização do desenvolvimento, ligado à infância e suas vicissitudes (BIAGGIO, 1988).

\section{Primeira Infância}

A Primeira infância se inicia com as primeiras sensações infantis sob a influência do ambiente externo, após o parto e segue durante os 3 (três) primeiros anos de idade da criança. Para Asbahr e Nascimento (2013) a criança na Primeira Infância aprende por ser possibilitada a aprender, consequenciando mudanças de comportamentos diante do vivido, repetido e comunicado. Os órgãos sensoriais captam as informações geradas por estes incentivos e posteriormente servirão de subsídios para a percepção da criança, isto é, como ela passa a interpretar o mundo. "Os sentidos de um recém-nascido estão em boas condições de funcionamento e ele vê e escuta o suficiente para detectar o que está acontecendo à sua volta e para reagir adaptativamente a muitas dessas sensações" (SHAFFER e KIPP, 2012, p. 178).

Aprofundando o trabalho desenvolvido de Shaffer e Kipp (2012) é exposto que autores como Streri, Lemoine e Devouche sinalizam que há na Primeira Infância uma maior tendência a habituação $o^{2}$, esta que já pode ser percebida desde a gestação, se tornando mais evidente após o nascimento, seguindo de modo intenso durante a Primeira Infância, onde o

\footnotetext{
${ }^{2}$ Processo pelo qual deixamos de dar atenção ou de reagir a um estímulo repetido. (STRERI, LEMOINE E DEVOUCHE, 2008) apud
} Shaffer e Kipp (2012, p.207, grifo do autor). 
amadurecimento cerebral acontece em uma velocidade maior que em demais fases do processo de desenvolvimento. É a partir dos estímulos aos quais a criança é submetida, que ela estabelece relação de respostas às exigências do seu meio circundante, possibilitando o desenvolvimento de habilidades físicas, motoras, cognitivas, emocionais, linguísticas e sociais.

Segundo Feldman e Papalia (2013), os recém nascidos já podem memorizar e aprender com as experiências sensoriais primeiras a partir do nascimento, os bebês não só reagem por um conjunto de reflexos inatos de sobrevivência, como piscar os olhos diante de intensa luz, mas por comportamentos aprendidos empiricamente e de modo cada vez mais elaborado e mais rapidamente compreendido e interpretado quando há mediação de um mundo que é percebido por ele como prazeroso e gratificante.

Os bebês já se preparam para a vida, desde cedo são bombardeados de informações, recebem múltiplos estímulos, buscam dar conta das exigências do seu mundo e do meio ao qual estão expostos e, aos poucos se adaptam e readaptam sempre diante de desafios que lhes são naturalmente postos. Além das necessidades básicas de sobrevivência que impulsionam respostas primeiras, a criança esta sujeita aos estímulos que agregam necessidades secundárias e exigem ações de comunicação com a mãe, com familiares, pessoas e objetos de seu ambiente social, que apontam para o desenvolvimento, considerado por Shaffer e Kipp (2012) como crescimento de:

[...] habilidades interpretativas: um processo complexo que depende do amadurecimento do cérebro e dos receptores sensoriais, dos tipos de experiências sensoriais que a criança tem disponível para analisar e interpretar, de suas emergentes habilidades motoras e até o contexto social, cultural no qual ela é criada (SHAFFER; KIPP, 2012, p. 214, grifo do autor).

As habilidades interpretativas da percepção são atribuídas ao desenvolvimento tipicamente saudável da criança ativa. É a criança o maior partícipe de seu próprio processo de desenvolvimento, os desafios são experienciados e enfrentados por ela, mas mediados pelo outro em seu ambiente. Ela vai lidar com a realidade dicotômica de ser ativo ou passivo, ser contínuo ou descontínuo, fazer uso de elementos inatos e adquiridos, vivenciará desafios constantes em seu ambiente social e, ainda paradigmas sociais e culturalmente construídos, daí a complexidade de compreender o desenvolvimento infantil, este deve ser analisado considerando-o como um processo holístico. (REEVE, 2006). 
A criança vivencia um processo constante de apreensão e, passa a exprimir comunicação e padrão de expressões de forma autêntica ao seu ambiente, em meio às tentativas de dar conta das respostas às quais ela esta sendo estimulada.

$\mathrm{O}$ processo de desenvolvimento do ser humano toma em si as singularidades humanas, as especificidades hereditárias do indivíduo e aquelas que são resultantes da sua experiência de interação com a realidade social e física (DIAS; CORREIA; MARCELINO, 2013, p.14).

É a partir dessa interação do inato e do adquirido que Romani e Lira (2014) postulam as diversas formas de aprendizagem dos bebês no começo da vida, em sua Primeira Infância e o desenvolvimento progressivo das habilidades de interpretação de si e do mundo.

Os múltiplos fatores que se apresentam como possíveis interventores podem está relacionados a crenças, tradições e culturas territoriais e familiares. Segundo Asbahr e Nascimento (2013), o meio ambiente é potencialmente socializante, a criança aprende na interação com as pessoas, com objetos, com animais, com sons, cores, gestos, aprende até quando os móveis da casa são mudados de lugar ou novas pessoas passam a conviver com as mesmas, há mudanças e ativações psicológicas do seu mundo interno.

[...] a aprendizagem e o desenvolvimento são facilitados pelo envolvimento das pessoas em uma interação, gerando padrões de relação que se tornam paulatinamente mais complexos em função das atividades recíprocas desenvolvidas e das relações afetivas estabelecidas de maneira sólida e duradoura (POLONIA; DESSEN; SILVA, 2005, p.76).

Estas mudanças acontecem com quem também convive com as crianças, quando os mesmos sentem-se vinculados a mesma, seja na adequação do tempo de dedicação ou na reconfiguração de identidade e papéis nas funções familiares. Acrescenta ainda que as mudanças no ambiente pela presença da criança se revelam no retorno destes cuidadores às suas reminiscências e recordações infantis, no resgate lúdico, quando bate palmas, brincam e cantam músicas, voltam a passear no parquinho e reveem o colorido do mundo nas árvores e animais, transmitindo estas informações impregnadas de emoções e significados para a criança que capta atenta e passionalmente.

Então, a necessidade de cuidados especiais demanda interação e colaboração dos mediadores do meio ambiente. Segundo Biaggio (1988) o bebê solicita ser socializado para que consolide ao longo dos próximos ciclos vitais a sua individuação. Especificamente nas primeiras semanas de vida, segundo o autor, o recém nascido necessitará de um útero 
Id on Line Revista Multidisciplinar e de Psicoloqia

Id on Line Multidisciplinary Journal and Psycology

psicológico para o progressivo processo de adaptação social. Com o seguir dos meses, a complexidade das experiências, desde as alimentares aos intercâmbios interrelacionais, contribuem para a organização psíquica interna pela realidade externa, proporcionando maturações para com seu ambiente.

\section{Infância e família}

No processo de desenvolvimento da criança, a família exerce papel imensurável, mas por muito tempo não era reconhecido como tal. A compreensão do sentimento de família é ascendida em meados do século XVII e foi divisor de águas para que os cuidados com a infância constituíssem um status subjetivo, com a percepção legal sobre o respeito e reconhecimento da criança como membro integrante do núcleo familiar, a quem se daria importância de promover os vínculos e garantir responsabilizações da família e do estado sobre a educação, a saúde e o bem estar da criança (ÀRIES, 1981).

No contato com o mundo a criança estabelece cada vez mais relação com pessoas, objetos e muitos outros estímulos que vão caracterizando o processo de socialização em seu desenvolvimento. As primeiras experiências sociais da criança são na família, desde o momento do parto o bebê já sofre influência social, mas as respostas do bebê ainda são simples, e podemos pressupor que há concretização do início de uma vida biopsicossocial. Gradualmente a criança interage e responde as necessidades internas e externas, adaptando-se ao meio, as pessoas e ao contexto, assim passamos a considerar como atos sociais, bem como percebermos as influencias que esses atos tem sobre o agir e o desenvolver da criança.

A família oferece as primeiras experiências sociais à criança, mãe, pai, irmãos, tios, avós, passam a responder as necessidades básicas de fome, sede, sono, dor seguindo de necessidades sociais $^{3}$ (REEVE, 2006, p.105), aquelas adquiridas a partir das experiências vivenciadas nesse processo de socialização: fome + carinho (desde a amamentação), sede + brincadeira (copos coloridos, faz de conta que dar água, pede sorrisos), sono + atenção (balançar para dormir, cantar, colocar paninho ao lado do rosto, chupeta), elogios, exaltação,

\footnotetext{
${ }^{3}$ Um processo psicológico adquirido que se intensifica a partir da própria história de socialização da pessoa e que ativa as respostas emocionais dadas por ela a incentivos relevantes à necessidade. Exemplos incluem as necessidades de realização, afiliação, intimidade e poder. (REEVE, 2006, p.105). 
Id on Line Revista Multidisciplinar e de Psicologia

Id on Line Multidisciplinary Journal and Psycology

sorrisos, respostas afirmativas às ações da criança, se estendendo ao longo do processo de desenvolvimento, denotando consequentemente o caráter afetivo da relação. "Os afetos podem ser positivos, negativos, mútuos, siméricos ou complementares" Bronfennbrenner (1979/1996 apud DESSEN e COSTA JUNIOR, 2005, p75).

\begin{abstract}
Sabemos que a criança se desenvolve em vários contextos com características específicas, isto é, com regras, atitudes, valores e modos de estar e ser concretos. Desde o primeiro dia em que vem ao mundo, o ser humano começa a ter consciência de que existe um mundo externo a si. É nesse mundo que aprende sobre si, a estar e a comunicar-se com os outros. Neste sentido, a primeira infância é um período de mudanças significativas no que diz respeito ao desenvolvimento social (DIAS; CORREIA; MARCELINO, 2013, p.13).
\end{abstract}

O Ambiente familiar é o primeiro ambiente social da criança, esse deve ser rico em estimulação para com as experiências primeiras, dentre elas as que potencializam o desenvolvimento da linguagem, permitindo que a criança se comunique mais ativamente e com maior complexidade. Enquanto isso, o choro é o primeiro meio de comunicação do bebê, algumas expressões de sons vocais como "aah" começam a surgir entre 6 semanas e os 3 meses, seguindo com brincadeiras com os sons da fala de 3 à aproximadamente 6 meses, numa combinação com os sons que ouvem de pessoas que estejam ao seu redor. Entre os 6 e os 10 meses eis que surgem os balbucios, do tipo "ma-ma-ma" que para a família já representam as primeiras palavras do bebê, mas "balbucio não é linguagem real, pois não guarda significado para o bebê, mas ele se torna mais parecido com as palavras" (FELDMAN e PAPALIA, 2013, p.214).

A linguagem continua a se desenvolver através da imitação, até que torna-se paulatinamente compreendida e exprimem padrões semelhantes aos de sua cultura, dando sentido ao seu repertório de comunicação através da linguagem. Biaggio (1988) ressaltam que a linguagem é um ato social, onde a criança passa a se comunicar de modo cada vez mais elaborado e intencional com o seu ambiente, interagindo com as pessoas que com ela interagem, compondo mais um viés do desenvolvimento.

O desenvolvimento humano é estimulado o inibido pelo grau de interação com pessoas, que ocupam uma variedade de papeis, e pela participação e engajamento em diferentes ambientes. Quando a criança ta vivenciando uma experiência familiar, ela entra em contato com diferentes papeis como o de mãe, pai, irmãos, tios ou avós, e quando participa por exemplo, do espaço da creche e da casa tem a oportunidade de estabelecer repertórios distintos para cada um deles (POLONIA; DESSEN; SILVA, 2005, p.74). 
Id on Line Revista Multidisciplinar e de Psicoloqia

Id on Line Multidisciplinary Journal and Psycology

A criança quando estende seu contato para com outras crianças, outras pessoas e novos ambientes passam a desenvolver repertórios com características especialmente ligadas a esse contexto que intervém estabilidade do processo até então constituído, influindo mudanças para com a interação, se tornando mais evidente o desenvolvimento distinto que cara relação oferece. A personalidade passa a desenvolver-se também integrada as formas de agir em resposta às influencias inatas e ambientais, os bebês sinalizam personalidades distintas desde cedo, embora sejam semelhantes no que diz respeito a padrões de desenvolvimento, "desde o nascimento, o desenvolvimento da personalidade se entrelaça com os relacionamentos sociais" (FELDMAN e PAPALIA, 2013, p.231).

Quando se refere aos aspectos sociais do processo, faz-se necessário considera díade pessoa - ambiente e suas implicações. Se articularmos ao desenvolvimento psicossocial, nos reportaremos às contribuições de Erickson com sua teoria sustentada no pressuposto de que são períodos de crises que proporcionam avanço no desenvolvimento, temos acesso a oito estágios de desenvolvimento ou crises psicossociais para o desenvolvimento humano Confiança x desconfiança básica; Autonomia x vergonha e dúvida; seguidos de Iniciativa x culpa; Produtividade $\mathrm{x}$ inferioridade; Identidade $\mathrm{x}$ confusão de papéis; Intimidade $\mathrm{x}$ isolamento; Generatividade x estagnação; Integridade do ego x desespero - A solução bem sucedida desses conflitos permite vivenciar de modo satisfatório cada fase descrita por Erickson, caracterizando assim, o desenvolvimento psicossocial. (SHAFFER; KIPP, 2012)

Os dois primeiros dois estágios do desenvolvimento psicossocial Ericksoniano, que compreendem dois momentos integrados a Primeira Infância, Confiança versus Desconfiança Básica (Nascimento até 1 ano) e Autonomia versus Vergonha e Dúvida (1 a 3 anos), ou seja, de 0 a 3 anos. No primeiro estágio

O bebê aprende a confiar em outros para suprir suas necessidades básicas. Se seu cuidador rejeitá-lo ou for inconstante, a criança pode ver o mundo como um lugar ameaçador, cheio de pessoas não confiáveis. $\mathrm{O}$ agente social principal é o cuidador primário. (SHAFFER e KIPP, 2012, p.50).

A criança esta sob os cuidados de outro sujeito, genitor ou não, que deve exercer com eficiência o papel materno e/ou paterno favorecendo às resoluções de seus primeiros conflitos ligados ao processo de estabelecimento de confiança e se tornar inseguro diante da relações com o seu ambiente social. 
No segundo estágio, espera-se que a criança aprende a ser autônoma - a se alimentar e se vestir sozinha, a cuidar da própria higiene e assim por diante. Falha em alcançar essa independência pode forçá-la a duvidar de suas próprias habilidades e se sentir envergonhado. Os pais são os principais agentes sociais. Nesse momento, socializar é uma missão primordialmente familiar, acarretando exigências afetivas e condutas desses agentes sociais, dos espaços e necessidades emergentes na relação com seu ambiente (YUNES; JULIANO, 2010).

\section{Criança e Contextos: Dimensões da Infância para o Desenvolvimento}

$\mathrm{Na}$ possibilidade de integrar a criança à infância, intuímos a possibilidade de que conceitos são culturalmente determinados, quando consideramos o ambiente social ao qual a criança é submetida e o que este exprime historicamente em construto de paradigmas. Apreendemos as concepções de criança e de infância ao longo da história, e se torna indissociável do contexto no qual essa pode esta inserida, desde o ambiente familiar primeiro, exprime suas expectativas, desejos, padrões socioculturais e as demais exigências do meio, seguindo da possível compreensão teórica de estudos que tateiam experiências mensuráveis cronologicamente, psicologicamente e culturalmente implicados em um dado contexto $^{4}$. Desse modo não buscamos definir conceito de criança e/ou infância, mas uma exploração das vivencias da Primeira Infância e, como as experiências primeiras podem implicar no desenvolvimento (ÀRIES, 1981).

Nesse sentido, é feita aqui uma leitura do desenvolvimento humano pela perspectiva Bioecológica Bronfenbrenneana, contemplando os pressupostos desenvolvidos de 1977 à 1996, onde podemos considerar que as características biopsicológicas da pessoa estão ligadas ao processo de estabilidades e mudanças contínuas ao longo da vida e de gerações. Há um processo dialético pessoa - ambiente, que Bronfrenbrenner pressupôs haver uma interdependência na relação do indivíduo para com o seu ambiente, onde ambos influenciam e são influenciados mutuamente, permitindo compreensão processos interacionais, e ainda, seus efeitos de primeira e segunda ordem numa interpretação sistêmica dos processos evolutivos

${ }^{4}$ Contexto no sentido pressuposto por Bronfenbrenner no Modelo Bioecológico do Desenvolvimento Humano, que representa desde as interações imediatas/proximais (microssistema) a interações mais complexas/distais (exossistema). (grifo nosso). 
do individuo que caracterizam aspectos bidirecionais do desenvolvimento, que discutiremos a seguir, assim como a noção de contextos e seus respectivos ambientes de desenvolvimento, de acordo com o Modelo Bioecológico de Bronfenbrenner (BRONFENBRENNER, 2011).

Os estudos de Bronfenbrenner recebem influências de diversos modelos de conhecimento em ecologia do desenvolvimento humano, nos quais postulam a relação do indivíduo com o ambiente e suas respectivas implicações para com o desenvolvimento do mesmo. Não obstante, o Modelo Bioecológico integrou paradigmas até então sustentados, e nos oferece um perspectiva amplamente orientada ao processo, na tentativa de dar conta de investigações sobre as facetas do desenvolvimento humano em suas variadas dimensões; pessoa, processo, contexto e tempo são elementos fundamentais na compreensão das formulações teórica do modelo bioecológico de desenvolvimento humano.

\section{Contribuições Bioecológicas}

O Modelo Bioecológico do desenvolvimento apresentado por Urie Bronfennbrenner oferece uma perspectiva interacionista de compreensão da evolução humana, onde o desenvolvimento se da no contexto proporcionado na relação da pessoa com seus conteúdos genéticos e ambientais, considerando as influencias dialética do produto e do processo, onde o outro não é omisso, ele participa daquilo que ele executa, recebe influência quando influencia e seus efeitos tendem a transcender contexto de gerações (AFONSO; et al, 2015).

Nessa perspectiva, os efeitos bioecológicos acontecem em função do desenvolvimento, através de "sistemas sinérgicos que operam na dinâmica genéticaambiente" (POLONIA; DESSEN; SILVA, 2005, p.75). Os efeito ditos de primeira ordem, caracterizam a interação interpessoal de unidade mínima da díade, compartilhamento de atividades e/ou comportamentos onde manifestam influencias da interação, geralmente "envolvem as relações diretas e influências mútuas entre as pessoas, no seu processo evolutivo" (POLONIA; DESSEN; SILVA, 2005, p.76).

No que diz respeito aos efeitos de segunda ordem, um terceiro interage na díade, inibindo ou proporcionando significativamente as interações e padrões de comportamentos em desenvolvimento, como a relação mãe-bebê-pai-bebê-mãe e a relação marital para com a 
Id on Line Revista Multidisciplinar e de Psicoloqia

Id on Line Multidisciplinary Journal and Psycology

criança, bem como pessoas próximas não estão isentas da interação e influência nesse processo. O contexto expressa a influência da família, da cultura, da mídia, da tecnologia nos processos interacionais, onde os comportamentos revelam os vínculos e os efeitos que alteram os processos diádicos circunscritos na bidirecionalidade do desenvolvimento. A bidirecionalidade consiste em assegurar o processo interdependente do indivíduo e seu ambiente mutuamente influenciados, permitindo a compreensão dos efeitos e dos elementos que interagem numa conjuntura sistêmica para com os processos evolutivos (YUNES; JULIANO, 2010).

A característica ativa do indivíduo que interage como protagonista no núcleo do processo atua como agente de mudança de paradigmas unidimensionais, onde o ambiente influencia o indivíduo, sem que esse influencie inversamente. Quando o assunto é interação e influência, no sentido bronfennbrenneano, amplia-se os conceitos e se concebem contextos que subscrevem características da pessoa e do ambiente de forma concêntrica, onde o ambiente ecológico ${ }^{5}$ (POLONIA; DESSEN; SILVA, 2005, p.77, grifo do autor) dispõe a interação para o desenvolvimento.

Do ambiente ecológico, recortamos o ambiente mais imediato (microssitema) para compreendermos as interações na Primeira Infância, as influências e desenvolvimento. O microssistema bioecológico, configura o contexto mais próximo do indivíduo, "é constituído por padrões de atividade, papéis e relações interpessoais experienciados pelos indivíduos em um dado ambiente, no qual suas características físicas, sociais e simbólicas particulares funcionam de maneira a estimular ou inibir as relações interpessoais" (POLONIA; DESSEN; SILVA, 2005, p.79).

Desse modo, a criança nos primeiros três anos tem suas experiências prevalentes em microssistema, uma vez que são os ambientes imediatos que proporcionam os padrões iniciais de comportamentos, principalmente na interação mãe-bebê e com familiares. "O processo de desenvolvimento da criança é um processo pessoal, único, situado num contexto histórico e cultural que, também, o influencia. A criança desenvolve-se em diferentes ambientes, mais ou menos familiares, que lhe oferecem as suas primeiras experiências de vida" (DIAS; CORREIA; MARCELINO, 2013, p.14). As experiências vivenciadas são desafiadoras para o

\footnotetext{
${ }^{5}$ Ambiente ecológico é compreendido como um conjunto de estruturas concêntricas, onde cada uma abarca progressivamente a outra. Essas estruturas são chamadas micro, meso, exo, macro e cronossistema. 
Id on Line Revista Multidisciplinar e de Psicoloqia

Id on Line Multidisciplinary Journal and Psycology

desenvolvimento da criança, as interações no microssistema configuram também os desafios do ambiente social.

\section{Ambiente social da criança}

O convívio da criança tem em sua transversalidade em diversos aspectos sociais, constituído pela compreensão cultural e subjetiva dos indivíduos que interagem de modo imediato no ambiente social que se configura como palco de desafios para as experiências da criança desde o nascimento, provocando mudanças e constante (re)adaptação dos repertórios em resposta ao meio. A criança chega indefesa e é imediatamente exposta ao convívio social, já no momento do parto interage com o ambiente, sofrendo exigências do meio, assim, configurando o princípio de suas experiências para com o seu desenvolvimento. Para Feldman e Papalia (2013) a criança é vulnerável ao seu ambiente e suas relações, daí a importância de compreender o desenvolvimento a partir do contexto social.

Os aspectos sociais influem sobre o processo de desenvolvimento, de modo que a interação implica em constantes demandas para a criança, Bronfennbrenner e Morris (1998 apud NOBRE, 2013. p.47) expõe que demandas "são os aspectos que estimulam ou desencorajam as reações do ambiente social, favorecendo ou não o estabelecimento dos processos proximais". O ambiente social promove os desafios intervenientes no processo de desenvolvimento de modo intenso na Primeira Infância.

O processo de desenvolvimento deve ser de mudanças, progressos e conquistas em diversos domínios,

\footnotetext{
O desenvolvimento pessoal e social abrange as aptidões necessárias para a criança compreender e lidar com seus sentimentos, interagir com outras pessoas e afirmar-se como pessoa. Esse desenvolvimento baseia-se no seu relacionamento com os pais e outras pessoas, abrange o que ela pensa de si mesma, como aprendiz, e o seu sentido de responsabilidade perante si e os outros. Falar em desenvolvimento significa falar de uma mudança qualitativa, de uma alteração de comportamentos e atitudes. (CRÓ e PINHO, 2011. p.2)
}

O ambiente social, ao mesmo tempo em que é estimulante e desafiador. A relação mãe-bebê exige respostas coerentes da criança, pai e familiares próximos estão sempre interagindo verbalmente e/ou se expressando através de gestos, sons, objetos e cores, 
Id on Line Revista Multidisciplinar e de Psicoloqia

Id on Line Multidisciplinary Journal and Psycology

caracterizando-se como agente socializador da criança ao seu meio, configurando a interação e respostas aos aspectos desafiadores para a criança em seu ambiente (AFONSO et al, 2015). As primeiras experiências da criança são constantemente mediadas e, a própria mediação imprime estímulos desafiadores para o desenvolvimento.

\section{Considerações Finais}

A partir desse estudo, é possível compreender a Primeira Infância como fase determinante para todo o processo de desenvolvimento humano, é nesse período, geralmente compreendido do nascimento a aproximadamente os três anos de idade, onde a criança recebe os estímulos que irão cravar formas de responder ao mundo, reações e condutas posteriores refletirão as experiências vivenciadas nessa fase, em um processo contínuo de estabilidades e mudanças que indicarão características biopsicológicas do indivíduo ao longo do seu desenvolvimento.

Faz-se necessário ressaltar a importância das primeiras experiências para o desenvolvimento integral da criança. Os estímulos aos quais ela é submetida devem ser potencializadores do desenvolvimento de habilidades suficientes para essa fase, proporcionando ambiente no qual a criança se desenvolva, dada a condição minimizante de estímulos controladores que venham a inibi-la em seu processo. A família aqui exerce papel fundamental na mediação da relação criança-ambiente, facilitando o processo de adaptação e ajustamento no contato com seu meio social

A Primeira Infância, fase decisiva para o desenvolvimento, alicerçante para demais fases do processo, de modo que as experiências do contexto imediato, nas díades mãe-bebê, filho-pai, criança-família, ou seja, indivíduo-ambiente. Essa interação é reconhecida na concepção bioecológica do desenvolvimento, e contribui com uma compreensão bidimensional do sujeito e os respectivos efeitos da interação para com o desenvolvimento.

A criança estará em constante captação e interpretação de estímulos, permitindo experiências únicas e desafiadoras em seu ambiente social. Quando enfrentados e respondidos de modo satisfatório, as circunstancias desafiadoras constituem o cenário de desenvolvimento saudável na Primeira Infância, com qualidades autênticas, desenvolvidas diante das influências biopsicosociais que sinalizam implicações ao do desenvolvimento do sujeito, onde 
Id on Line Revista Multidisciplinar e de Psicologia

Id on Line Multidisciplinary Journal and Psycology

os desafios vivenciados nesta fase é condição sine quo non para os demais Ciclos do desenvolvimento.

O Ambiente social influencia no desenvolvimento de habilidades, de repertórios, de condutas. Desafios superados, "crises solucionadas" são sinônimos de desenvolvimento saudável, prenunciando condições favoráveis as experiências das demais do processo. $\mathrm{O}$ desenvolvimento saudável da criança advêm da capacidade de ajustar-se ao meio, superar desafios, minimizar crises, vivenciar satisfatoriamente as experiências da Primeira Infância.

\section{Referências}

AFONSO, Tatiana et al,. O uso do diário de campo na inserção ecológica em uma família de uma comunidade ribeirinha amazônica. Psicologia \& Sociedade. Belo Horizonte, v. 27, n. 1, p. 131141, abr. 2015. Disponível em: <http://www.scielo.br/pdf/psoc/v27n1/1807-0310-psoc-27-0100131.pdf> Acessado em: 01/02/2015.

ARIÈS, P. História Social da Criança e da Família. 2. Ed. Rio de Janeiro: LTC, 1981.

ASBAHR, F. da S. F.; NASCIMENTO, C. P. Criança não é Manga, não Amadurece: Conceito de Maturação na Teoria Histórico-Cultural. PSICOLOGIA: CIÊNCIA E PROFISSÃO, 33(2), 414-427. 2013. Disponível em: <http://www.scielo.br/scielo.php?pid=S141498932013000200012\&script=sci_arttext $>$. Acesso em 26/07/2014.

BIAGGIO, A. M. B. Psicologia do Desenvolvimento. Petrópoles: Vozes, 1988.

BRONFENBRENNER, U. Bioecologia do Desenvolvimento Humano: Tornando os Seres Humanos mais Humanos. Porto Alegre: Artmed, 2011.

CRÓ, M. L. ; PINHO, A. M. A Primeira infância e a avaliação do Desenvolvimento Pessoal e Social. Revista Ibero-americana de Educação. ISSN: 1681-5653. n. ${ }^{\circ}$ 56/1 - jul. 2011. Disponível em: <http://www.rieoei.org/deloslectores/3771Cro.pdf> Acessado em: 14/12/2014.

CUNHA, A. C. B da; BENEVIDES, J. Prática do Psicólogo em Intervenção Precoce na Saúde Materno-Infantil. Psicologia em Estudo, Maringá, v. 17, n. 1, p. 111-119, jan./mar. 2012.

DESSEN, M. A; COSTA JUNIOR, Á. L. A CIÊNCIA DO DESENVOLVIMENTO HUMANO Tendências atuais e perspectivas futuras. Porto Alegre: Artmed, 2005.

DIAS, I. S.; CORREIA, S.; MARCELINO, P. Desenvolvimento na primeira infância: características valorizadas pelos futuros educadores de infância. Revista Eletrônica de Educação. v. 7, n. 3, p.9-24. ISSN 1982-7199. 2013. Disponível em: <http://www.reveduc.ufscar.br/index.php/reveduc/article/viewFile/483/288> Acessado em: $14 / 09 / 2014$. 
Id on Line Revista Multidisciplinar e de Psicologia

Id on Line Multidisciplinary Journal and Psycology

FELDMAN, D. R; PAPALIA, D. E. Desenvolvimento Humano. 12. ed. Porto Alegre: AMGH, 2013.

LIMA, T. C. S.; MIOTO, R. C.T. Procedimentos metodológicos na construção do conhecimento científico: a pesquisa bibliográfica. Rev. katálysis, Florianópolis, v. 10, n. spe, 2007. Disponível em: <http://www.scielo.br/scielo.php?script=sci_arttext\&pid=S14 14-49802007000300004\&lng=en\&nrm=iso>. Acesso em: 16 de Setembro de 2014.

MÜLlER, F.; NUNES. B. F. Infância e Cidade: Um Campo de Estudo. Educ. Soc., Campinas, v. 35, nº. 128, p. 629-996, jul.-set., 2014.

NOBRE, F. S. S. Desenvolvimento Motor em Contexto: Contribuições do Modelo Bioecológico de Desenvolvimento Humano. (Dissertação). Porto Alegre: 2013

POLONIA, A. C; DESSEN, M. A; SILVA, N. P. O modelo bioecológico de Bronfenbrenner: contribuições para o desenvolvimento humano in DESSEN, M. A; COSTA JUNIOR, Á. L. A CIÊNCIA DO DESENVOLVIMENTO HUMANO Tendências atuais e perspectivas futuras. Porto Alegre: Artmed, 2005, p.71 - 89.

REEVE, J. M. Motivação e Emoção. Rio de Janeiro: LTC, 2006.

ROMANI, S. A. M,; LIRA, P. I. C. Fatores determinantes do crescimento infantil in Rev. Brasil. Saúde Materno Infantil. Recife: 2014. 4(1) 15-23, jan/mar 2014 Disponivel em: <http://www.scielo.br/pdf/rbsmi/v4n1/19978.pdf> Acesso em: 20/10/2014.

SHAFFER, D. R; KIPP, K. PSICOLOGIA DO DESENVOLVIMENTO Infância e Adolescência. São Paulo: CENGAGE Learning, 2012.

WINNICOTT, D. A criança e o seu mundo. 6. Ed. Rio de Janeiro: LTC, 1982.

YUNES, M. A. M.; JULIANO, M. C. A Bioecologia do Desenvolvimento Humano e suas Interfaces com Educação Ambiental in Cadernos de Educação. FaE/PPGE/UFPel. Pelotas [37]: 347 - 379, setembro/dezembro 2010. Disponível em: < http://periodicos.ufpel.edu.br/ojs2/index.php/caduc/article/viewFile/1591/1477> Acesso em: $31 / 01 / 2015$.

Como citar este artigo (Formato ABNT):

TEIXEIRA, A.N.; LÔBO, K.R.G.; DUARTE, A.T.C. A Criança e o ambiente social: aspectos intervenientes no processo de desenvolvimento na primeira infância. Id on Line Revista Multidisciplinar e de Psicologia, SetOut de 2016, vol.10, n.31, Supl 2, p. 114-134. ISSN 1981-1179.

Recebido: 05/09/2016

Aceito: 15/09/2016 